\title{
Significance of early diagnosis of abdominal compartment syndrome in major burns
}

\author{
C Levis MD MSc FRCSC ${ }^{1}$, F Ali MD ${ }^{2}$
}

\begin{abstract}
C Levis, F Ali. Significance of early diagnosis of abdominal compartment syndrome in major burns. Can J Plast Surg 2006;14(3):175-178.

Four cases of abdominal compartment syndrome in patients suffering major burns, who were treated at Hamilton General Hospital, Hamilton, Ontario, from January 1998 to June 2003, are reported. The pathophysiological changes, and the high morbidity and mortality associated with this condition are also described. The significance of early diagnosis of this syndrome is discussed. The literature is reviewed and a protocol is suggested for measuring urinary bladder pressure when managing major burns.
\end{abstract}

\section{La signification d'un diagnostic précoce de syndrome des loges sur l'abdomen causé par de graves brûlures}

\begin{abstract}
Quatre cas de syndrome des loges sur l'abdomen chez des patients atteints de graves brûlures soignés au Hamilton General Hospital de Hamilton, en Ontario, entre janvier 1998 et juin 2003, sont exposés. Les modifications physiopathologiques et le taux élevé de morbidité et de mortalité associé à ce trouble sont également décrits. L'importance de poser un diagnostic précoce est évaluée. On passe en revue les publications et on suggère un protocole pour mesurer la pression de la vessie urinaire dans la prise en charge des graves brûlures.
\end{abstract}

Key Words: Abdominal compartment syndrome; Intra-abdominal pressure

bdominal compartment syndrome (ACS) is a rare compliAcation of major burns, and its occurrence in the burn literature has not been widely reported. Since the late 19th century, numerous experimental studies have described the adverse physiological effects of elevated intra-abdominal pressure (IAP), including impaired cardiac function, decreased pulmonary compliance and decreased renal perfusion.

In 1890, Heinricans demonstrated that respiratory dysfunction and death were associated with increased IAP in feline and porcine models (1). Emerson (2), in 1911, described the cardiovascular changes associated with increased IAP. Soon thereafter, in 1913, Wendt described the effect of increased IAP on renal perfusion and function (3). All of these experimental studies confirmed the effects of increased IAP on multiple organ systems. In 1983, Richards et al (4) described a small series of patients who developed abdominal distension and anuria after major abdominal trauma, requiring decompression laparotomy; however, the term 'abdominal compartment syndrome' was first used by Kron et al in 1984, who identified a direct relationship between urinary bladder pressure and IAP (5).

The incidence of ACS in burn patients is relatively low. In 1994, Greenhalgh and Warden (6) described the importance of IAP measurement in 30 children with major burns. They noted that the incidence of ACS increased with burn size and depth. In 1999, Ivy et al (7) described ACS in patients with burns to more than $70 \%$ of the body surface area (BSA), and recommended measuring bladder pressure after infusion of more than $0.25 \mathrm{~L} / \mathrm{kg}$ of fluid during the acute resuscitation phase, and for peak inspiratory pressures (PIPs) greater than $40 \mathrm{~cm} \mathrm{H}_{2} \mathrm{O}$ (7). In 2002, Hobson et al (8) concluded that surgical release of the abdomen improved survival in major burn patients, and recommended abdominal decompression in any patient who developed ACS and urinary bladder pressure greater than $30 \mathrm{mmHg}$. In 2002, Latenser et al's pilot study (9) compared percutaneous decompression with decompressive laparotomy in burn patients. Percutaneous decompression was found to be a safe and effective method of decreasing IAP and preventing ACS in patients with thermal injury.

\section{Case 1}

\section{CASE PRESENTATIONS}

A 35 -year-old man sustained burns to $45 \%$ of his BSA, involving his face, chest and bilateral extremities, secondary to a grease fire in his kitchen. He was otherwise well, except for a significant history of heavy smoking. He was transferred from a peripheral emergency room to Hamilton General Hospital, Hamilton, Ontario. After intubation and commencement of fluid resuscitation, admission blood work revealed a volumecontracted state with a hemoglobin level of $187 \mathrm{~g} / \mathrm{L}$. He required aggressive fluid resuscitation, receiving a total of $35 \mathrm{~L}$ of Ringer's lactate in the first $24 \mathrm{~h}$ of admission to the burn unit. Gradually, his hemoglobin level normalized to $150 \mathrm{~g} / \mathrm{L}$.

Twenty hours after his admission, the patient became acidotic with increasing abdominal distension, swelling of his extremities requiring escharatomies, and a decrease in urinary output to less than $17 \mathrm{~mL} / \mathrm{h}$. His urinary bladder pressure was measured at $58 \mathrm{mmHg}$. Despite chemical paralysis with succinylcholine, ventilation was difficult. His PIP increased to $55 \mathrm{~cm} \mathrm{H} \mathrm{H}_{2} \mathrm{O}$. The general surgery service was consulted for management of ACS, and immediate decompression laparotomy was recommended. The patient was taken to the operating

${ }^{1}$ St Joseph's Health Care; ${ }^{2}$ Division of Plastic Surgery, Department of Surgery, Hamilton Health Sciences, McMaster University, Hamilton, Ontario

Correspondence: Dr Carolyn Levis, St Joseph's Health Care, Fontbonne Building, Room 545, 50 Charlton Avenue East, Hamilton, Ontario L8N 4A6. Telephone 905-308-9419, fax 905-525-6424, e-mail levisc@mcmaster.ca 
TABLE 1

Characteristics and outcomes of four patients with abdominal compartment syndrome following major burns

\begin{tabular}{|c|c|c|c|c|}
\hline & Case 1 & Case 2 & Case 3 & Case 4 \\
\hline Age, years & 35 & 57 & 38 & 31 \\
\hline Sex & Male & Male & Male & Female \\
\hline Total body surface area, $\%$ & 45 & 20 & 30 & 50 \\
\hline Site & $\begin{array}{l}\text { Face, neck, chest } \\
\text { bilateral upper limbs }\end{array}$ & $\begin{array}{c}\text { Half back, right shoulder } \\
\text { left lateral arm }\end{array}$ & $\begin{array}{l}\text { Right arm, bilateral feet, } \\
\text { bilateral buttocks }\end{array}$ & $\begin{array}{l}\text { Head and neck, chest, abdomen, } \\
\text { right arm, bilateral thighs }\end{array}$ \\
\hline Surgical decompression & Yes & No & No & Yes \\
\hline Complication & Oliguria & $\begin{array}{l}\text { Acute renal failure, acute } \\
\text { respiratary distress syndrome }\end{array}$ & $\begin{array}{l}\text { Superior vena cava syndrome, } \\
\text { cardiac tamponade }\end{array}$ & Sepsis, multiorgan failure \\
\hline Survival & Yes & No & No & No \\
\hline
\end{tabular}

room for a laparotomy, and several litres of clear abdominal fluid were drained. Moderate edema of the bowel and mesentery was noted. Vicryl mesh was placed, and the wound was subsequently treated with moist daily dressings. His vital signs, urine output and lung compliance improved intraoperatively, and his urine output further improved within $2 \mathrm{~h}$ of surgery. The patient stabilized with respect to his abdominal status, and he required subsequent trips to the operating room for debridment and skin grafting for his burns. Three weeks later, when granulation tissues had developed, the laparotomy wound was skin grafted. The patient's general condition improved and he was discharged home after four weeks.

\section{Case 2}

A 57-year-old man was involved in a house fire and sustained second-and third-degree burns to $20 \%$ of his BSA, involving his right shoulder, left lateral arm and one-half of his back. He had no comorbidities. Fluid resuscitation began as soon as he arrived at the Hamilton General Hospital emergency room. He was intubated and admitted to the burn unit. He received a total of $30 \mathrm{~L}$ of Ringer's lactate in the first $24 \mathrm{~h}$ of his admission. Twenty-three hours after his admission, he became anuric, with a creatinine level of $180 \mu \mathrm{mol} / \mathrm{L}$. Ventilation became difficult, requiring jet ventilation, and his abdomen became tense. The urinary bladder pressure was $45 \mathrm{mmHg}$ and ACS was diagnosed. He was immediately taken to operating room for decompression laparotomy. Unfortunately, $25 \mathrm{~h}$ postoperatively, he started to deteriorate and developed multiorgan failure. Care was withdrawn at the request of his family.

\section{Case 3}

A 38-year-old man sustained scald burns to $30 \%$ of his BSA, involving bilateral feet, buttocks, back and posterior arms. His medical history was significant for cerebral palsy, epilepsy and glaucoma. He has been at an institution in a bathtub (unattended) and the hot water was turned on. He was transferred to Hamilton General Hospital from a peripheral emergency department, where fluid resuscitation was initiated. On arrival to the authors' emergency room, fluid resuscitation was continued, and the patient was intubated and admitted to the burn unit, where he received a total of $15 \mathrm{~L}$ of Ringer's lactate in the first $24 \mathrm{~h}$. Eighteen hours after his admission, he started to deteriorate. His abdomen became distended, urinary output decreased to $15 \mathrm{~mL} / \mathrm{h}$ and the PIP increased to $52 \mathrm{~cm} \mathrm{H}_{2} \mathrm{O}$. The urinary bladder pressure was $25 \mathrm{mmHg}$ and ACS was suspected. He developed superior vena cava syndrome, and while waiting for an emergent echocardiogram, he deteriorated and underwent a bradycardic arrest. Resuscitation was attempted, and a thoracotomy was performed. The patient was taken to the operating room where he was, unfortunately, pronounced dead upon arrival.

\section{Case 4}

A 31-year-old woman was involved in a house fire, sustaining burns to $50 \%$ of her BSA, including her head, anterior trunk, bilateral arms and thighs, as well as an inhalation injury. Initial resuscitation began in another medical centre, where she had been intubated, and she was then transferred to Hamilton General Hospital by air ambulance. She was admitted to the burn unit and fluid resuscitation was continued. She received a total of $18 \mathrm{~L}$ of Ringer's lactate in the first $24 \mathrm{~h}$. Over the following six weeks, she developed multiorgan failure and ischemia of the right leg, requiring angioplasty. She also required several surgeries for debridment and skin grafting.

Six weeks after admission, her abdomen became distended, urinary output decreased to $10 \mathrm{~mL} / \mathrm{h}$ to $15 \mathrm{~mL} / \mathrm{h}$, the PIP increased to $50 \mathrm{~cm} \mathrm{H}_{2} \mathrm{O}$ and ACS was diagnosed. Percutaneous decompression was performed to relieve the high IAP. However, her general condition failed to improve and care was withdrawn at the request of her family.

\section{RESULTS}

A review of patients admitted to the burn unit at Hamilton General Hospital from January 1998 to June 2003 resulted in four cases of ACS. Three of these patients had early-onset ACS that occurred within the first $24 \mathrm{~h}$ to $48 \mathrm{~h}$, and the fourth patient had late-onset ACS that occurred six weeks after the burn injury, secondary to a tight abdominal wall due to previous skin grafting. Two of the four patients developed ACS in the absence of thoracoabdominal burns. All four patients received aggressive fluid resuscitation. Three of four patients had decompressive laparotomies and one patient had percutaneous decompression. The mortality rate was $75 \%$. Three of four patients died in spite of early diagnosis and aggressive management. In the authors' burn unit, urinary bladder pressure management is not routinely measured in major burns unless there is a sign of increased IAP pressure, such as abdominal distension, oliguria, decreased lung compliance and increased PIPs. Results are summarized in Table 1.

\section{DISCUSSION}

ACS is a rare complication of severe burn injury. There are few studies in the literature evaluating the significance of early diagnosis of ACS in major burns. Most of these studies indicate 


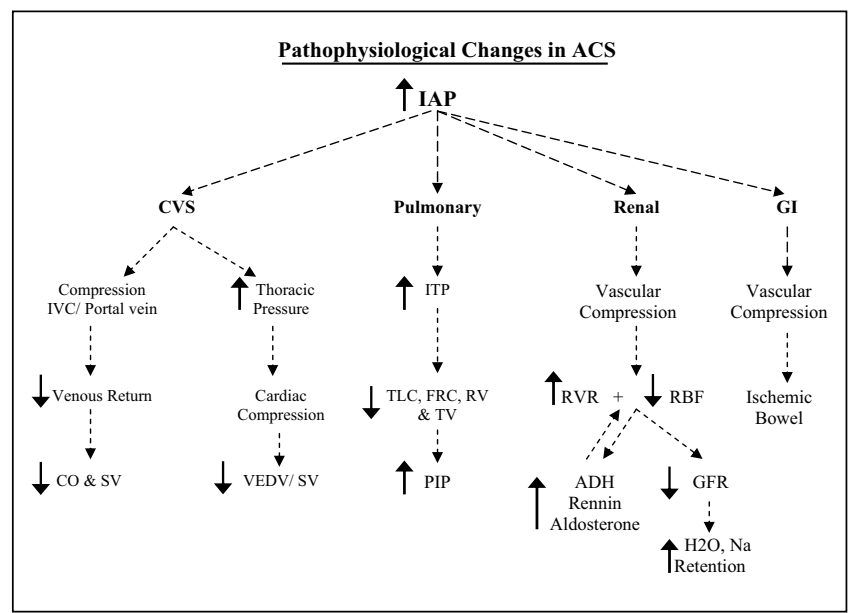

Figure 1) Pathophysiological changes in abdominal compartment syndrome (ACS). ADH Antidiuretic hormone; CO Cardiac output; CVS Cardiovascular system; FRC Forced residual capacity; GFR Glomerular filtration rate; GI Gastrointestinal; IAP Intra-abdominal pressure; ITP Intrathoracic pressure; IVC Inferior vena cava; PIP Peak inspiratory pressure; RBF Renal blood flow; RV Residual volume; RVR Renovascular resistance; SV Stroke volume; TLC Total lung capacity; TV Total volume; VEDV Ventricular end-diastolic volume; $\uparrow$ Increased; $\downarrow$ Decreased

that ACS is a fatal complication if it is not diagnosed and managed early.

The risk factors for ACS in burns are not completely clear; however, the risk increases with increasing BSA and depth of burn (6). Aggressive fluid resuscitation in the early resuscitative period is presumed to be a risk factor, because it may result in excessive third spacing of fluid. As well, deep or circumferential burns to the abdomen and thorax increase the risk. This has been reported by Ivy et al (7), who suggested urinary bladder pressure measurement after infusion of more than $0.25 \mathrm{~L} / \mathrm{kg}$ during the acute resuscitation phase. Patients with circumferential torso burns can develop ACS, and require early abdominal wall escharotomy and, subsequently, decompressive laparotomy if the syndrome develops.

To better understand the clinical presentation and management of ACS, one must understand the pathophysiological changes associated with this syndrome in each organ separately (Figure 1).

Cardiovascular derangements in ACS are a result of the elevated IAP. This effect is consistently seen when the IAP is greater than $20 \mathrm{mmHg}$. Elevation of IAP causes direct compression on the inferior vena cava and portal vein. Elevation of IAP also leads to elevation of the diaphragm, which increases intrathoracic pressure. The end results of these effects include decrease in cardiac output, ventricular end-diastolic volume, stroke volume and impairment in venous return. Reduction in static and dynamic pulmonary compliance is one of the clinical features of ACS (5).

When the intrathoracic pressure increases, total lung capacity, functional residual capacity and residual volume decrease. Therefore, if a patient is on volume cycle ventilation, the PIP gradually starts to increase and the patient eventually will have difficulty in ventilation. Oliguria and anuria in ACS is thought to be due to direct renal compression. An increase in the IAP greater than $15 \mathrm{mmHg}$ decreases renal circulation and increases renal vascular resistance. Elevation of the IAP

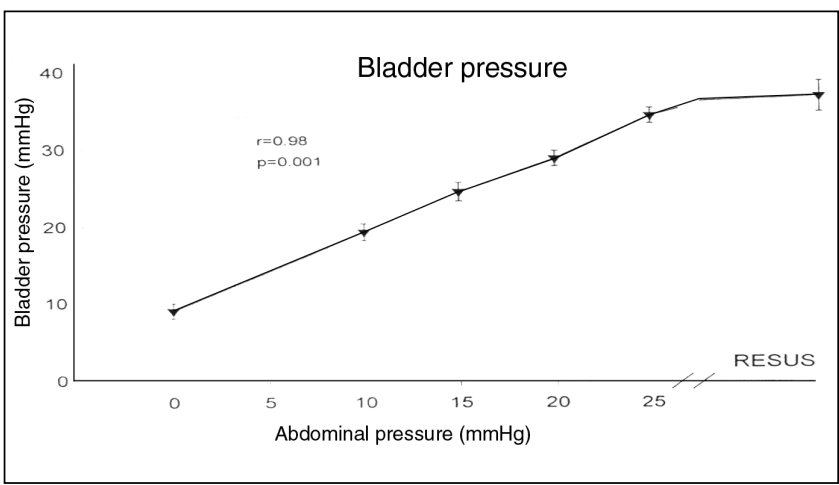

Figure 2) Correlation between urinary bladder pressure and directly measured intra-abdominal pressure. Reprinted with permission from (5). Resus Resuscitation

greater than $20 \mathrm{mmHg}$ decreases splanchnic circulation, and impairs mesenteric and hepatic blood flow. Elevation of the IAP has also been reported to increase intracranial pressure and decrease cerebral perfusion pressure, leading to brain ischemia. The IAP is normally negative (5).

Three different, indirect methods of estimating IAP have been suggested. These indirect methods include gastric, inferior vena cava and urinary bladder pressure measurements. Gastric pressure measurement is not advisable because of its significant discrepancy at higher IAPs. Inferior vena cava pressure is impractical and invasive, and has not been used in human studies. Urinary bladder pressure, first described by Kron et al (10) for indirect clinical measurement of IAP, was found to correlate well with increasing IAP (Figure 2).

Most studies on ACS in burns imply that intra-abdominal hypertension occurs even before the development of ACS. Therefore, it is advisable to attempt to control intra-abdominal hypertension using nonoperative measures, including flushing the bladder catheter to ensure patency, nasogastric tube insertion, and escharotomies of any existing circumferential or constricting abdominal wounds. Sedation and even pharmacological paralysis can be helpful in lowering the IAP. However, if these nonoperative measures are implemented and the patient nonetheless develops an IAP greater than $30 \mathrm{mmHg}$ in conjunction with signs of overt ACS, including high PIP, difficulty in ventilation, oliguria and abdominal distention, abdominal decompression should be performed immediately, either percutaneously or by laparotomy. Open decompression is mandatory in ACS, and nonoperative measures should be reserved for patients with intra-abdominal hypertension.

There is no doubt that ACS in major burns is a fatal complication if it is not managed immediately. Therefore, we strongly recommend the incorporation of bladder pressure measurements as part of the resuscitation protocol for all major burns. We recommend urinary bladder pressure measurement every $4 \mathrm{~h}$ in the first $24 \mathrm{~h}$ for the patient who meets the following criteria: presents in the first $24 \mathrm{~h}$ of burn injury, has major burns with or without inhalation injury, had massive fluid resuscitation in the first $24 \mathrm{~h}$, has thoracoabdominal burns and comorbidities.

There are few studies that have reported ACS in burn patients. It is unclear which patients are at high risk, whether if massive fluid resuscitation increases the risk of ACS and 
whether early open decompression or prophylactic percutaneous drainage yields better outcomes. There may be a role for prophylactic minilaparotomy in those who have a gradual increase in their urinary bladder pressure. Therefore, a large, properly designed, multicentre, randomized trial is needed to answer these questions.

\section{REFERENCES}

1. Coombs HC. The mechanism of the regulation of intra-abdominal pressure. Am J Physiol 1920;61:159-63.

2. Emerson H. Intra-abdominal pressures. Arch Intern Med 1911;7:754-84.

3. Abeshouse BS. Renal decapsulation: A review of the literature and a report on ten cases. J Urol 1945;53:27-32.

4. Richards WO, Scovill W, Shin B, Reed W. Acute renal failure associated with increased intra-abdominal pressure. Ann Surg 1983;197:183-7.

5. Saggi BH, Sugerman HJ, Ivatury RR, Bloomfield GL. Abdominal compartment syndrome. J Trauma 1998;45:597-606.

6. Greenhalgh DG, Warden GD. The importance of intra-abdominal pressure measurements in burned children. J Trauma 1994;36:685-90.

7. Ivy ME, Atweh NA, Palmer J, Possenti PP, Pineau M, D'Aiuto M. Intra-abdominal hypertension and abdominal compartment syndrome in burn patients. J Trauma 2000;49:387-91.
8. Hobson KG, Young KM, Ciraulo A, Palmieri TL, Greenhalgh DG. Release of abdominal compartment syndrome improves survival in patients with burn injury. J Trauma 2002;53:1129-34.

9. Latenser BA, Kowal-Vern A, Kimball D, Chakrin A, Dujovny N. A pilot study comparing percutaneous decompression with decompressive laparotomy for acute abdominal compartment syndrome in thermal injury. J Burn Care Rehabil 2002;23:190-5.

10. Kron IL, Harman PK, Nolan SP. The measurement of intraabdominal pressure as a criterion for abdominal re-exploration. Ann Surg 1984;199:28-30.

\section{RECOMMENDED READING}

- Kashtan J, Green JF, Parsons EQ, Holcroft JW. Hemodynamic effect of increased abdominal pressure. J Surg Res 1981;30:249-55.

- Richardson JD, Trinkle JK. Hemodynamic and respiratory alterations with increased intra-abdominal pressure. J Surg Res 1976;20:401-4.

- Cullen DJ, Coyle JP, Teplick R, Long MC. Cardiovascular, pulmonary, and renal effects of massively increased intra-abdominal pressure in critically ill patients. Crit Care Med 1989;17:118-21.

- Richards WO, Scovill W, Shin B, Reed W. Acute renal failure associated with increased intra-abdominal pressure. Ann Surg 1983;197:183-7. 